\title{
Nasal septal abscess with a dental origin: a case report and a review of the literature
}

\author{
Sang Min Lee, Dae Ho Leem \\ Department of Oral and Maxillofacial Surgery, School of Dentistry, Research Institute of Clinical Medicine of Jeonbuk National \\ University-Biomedical Research Institute of Jeonbuk National University Hospital, Jeonju, Korea
}

\begin{abstract}
J Korean Assoc Oral Maxillofac Surg 2021;47:135-140)
Since the first report of a nasal septal abscess (NSA) from a dental origin (1920), six articles have been published in the English literature to date. The most common cause of NSA is an infection of the nasal septal hematoma after trauma. This is a report of an uncommon cause of NSA with a dental origin. A PubMed search performed regardless of year and country using the terms ("nasal septal abscess") OR ("nasal septum abscess") initially yielded 229 articles. After screening, seven articles (eight patients) were selected. Addition of two related articles produced a total of nine articles (10 patients) to be included. The age of the included patients ranged from 7 to 69 years (mean, 32.82 years; standard deviation, \pm 23.86 years). The sex composition was as followed: males $(n=7 ; 63.6 \%)$, females $(n=4 ; 36.4 \%)$. Dental histories were various: periapical lesions, caries, extraction, endodontic therapy, and cystic lesions. The maxillary incisor dominated as the tooth of origin. Early diagnosis and treatment of NSAs are important to avoid not only facial deformity, but also severe complications (e.g., intracranial infection). If NSA is suspected in patients without facial trauma, the possibility of a dental origin, especially from the maxillary incisor area, should be considered.
\end{abstract}

Key words: Nasal septal abscess, Dental focal infection

[paper submitted 2019. 6. 23 / revised 2019. 8. 19 / accepted 2019. 9. 11]

\section{Introduction}

Nasal septal abscess (NSA) with a dental origin is uncommon $^{1}$. In 1920, McKenzie ${ }^{2}$ reported a case of NSA originating from an alveolar abscess of the right upper lateral incisor. Since then, six articles have been published in the English literature $^{1-6}$.

NSA is defined as a collection of pus located between the nasal bony or cartilaginous septum and the mucoperichondrium or mucoperiosteum ${ }^{6,7}$. Although NSA is uncommon, immediate therapy is indicated to avoid complications such as facial deformity or intracranial infection ${ }^{8}$. Treatments include antibiotic coverage and surgical drainage including diagnostic

\section{Dae Ho Leem}

Department of Oral and Maxillofacial Surgery, School of Dentistry, Jeonbuk National University, 567 Baekje-daero, Deokjin-gu, Jeonju 54896, Korea TEL: +82-63-250-2808

E-mail:idisho@jbnu.ac.kr

ORCID: https://orcid.org/0000-0001-6735-8275

(c) This is an open-access article distributed under the terms of the Creative Commons Attribution Non-Commercial License (http://creativecommons.org/ licenses/by-nc/4.0/), which permits unrestricted non-commercial use, distribution, and reproduction in any medium, provided the original work is properly cited. Copyright (C) 2021 The Korean Association of Oral and Maxillofacial Surgeons. All rights reserved. needle aspiration ${ }^{8}$. In 1945, Beck ${ }^{9}$ classified the etiology of NSAs into three categories: nasal trauma, sinonasal or dental infection, and spontaneous occurrence without an underlying cause. Among these, the most common cause of NSA is an infection of the nasal septal hematoma after accidental or surgical nasal trauma ${ }^{8-11}$. Herein, we report a case of uncommon presentation of NSA with a dental origin in a patient with a history of left upper central incisor extraction 4 days prior.

\section{Case Report}

A 64-year-old female patient with no immunodeficiency or history of trauma visited Jeonbuk National University with the chief complaint of nasal cavity swelling. The patient had no other underlying disease except controlled diabetes mellitus for 13 years with medication. On the first visit, laboratory testing for diabetes indicated the following: HbA1c, $6.5 \%$ and serum glucose, $158 \mathrm{mg} / \mathrm{dL}$. Nasal obstruction had begun 4 days previous, when her left upper central incisor was extracted. On physical examination, reddish bulging around the nasal septum was observed. The patient reported discomfort with nasal breathing due to the obstruction.(Fig. 1) There was 


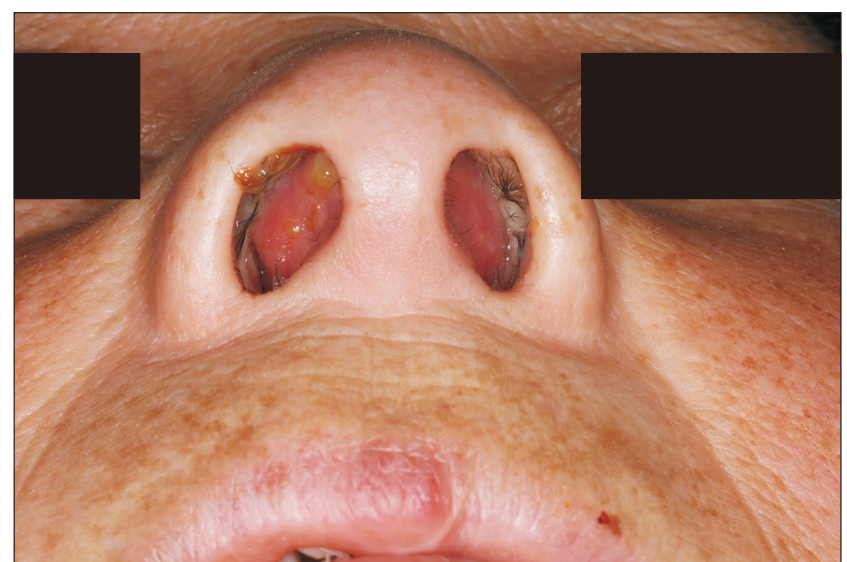

Fig. 1. Clinical photograph at first visit. Reddish swelling on both sides were observed around the nasal septum.

Sang Min Lee et al: Nasal septal abscess with a dental origin: a case report and a review of the literature. J Korean Assoc Oral Maxillofac Surg 2021

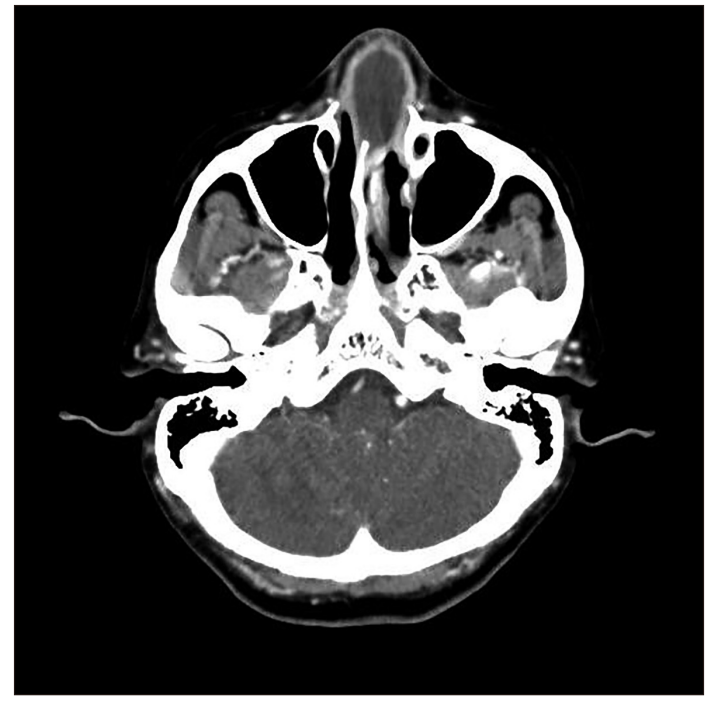

Fig. 2. Enhance computed tomography (coronal view). The lesion size in the anterior portion of the nasal septum is $31 \mathrm{~mm} \times 27 \mathrm{~mm} \times$ $39 \mathrm{~mm}$.

Sang Min Lee et al: Nasal septal abscess with a dental origin: a case report and a review of the literature. J Korean Assoc Oral Maxillofac Surg 2021

no pus discharge around the extracted tooth. On needle aspiration of the nasal septal area, a relatively transparent brownish fluid was observed.

As a result of facial computed tomography (CT) with enhancement (Fig. 2), she was diagnosed with NSA. Triple antibiotic therapy with piperacillin sodium/sulbactam sodium, metronidazole, and amikacin was immediately initiated after admission. Medication dosage and method used were as follows: combicin $3 \mathrm{~g}$ (Samsung, Hwaseong, Korea; two vials, three times a day, intravenously), metronidazole $0.5 \mathrm{~g} / 100$ $\mathrm{mL} / \mathrm{Bag}$ (CJ HealthCare, Seoul, Korea; one vial, three times a

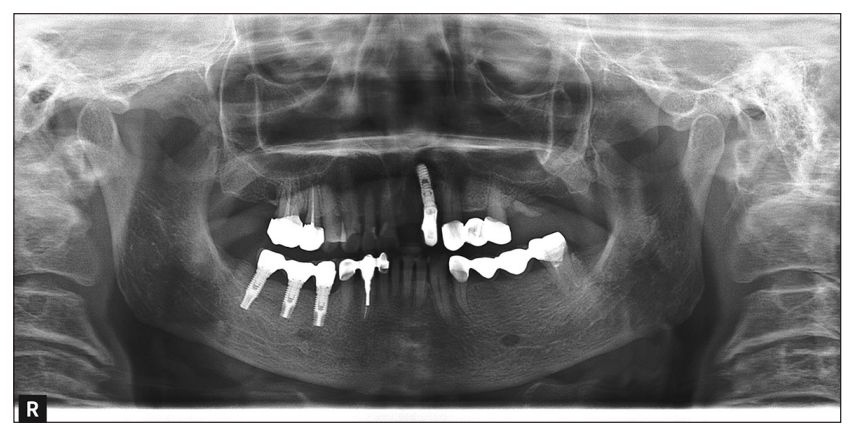

Fig. 3. Panoramic view. Left maxillary central incisor was extracted.

Sang Min Lee et al: Nasal septal abscess with a dental origin: a case report and a review of the literature. J Korean Assoc Oral Maxillofac Surg 2021

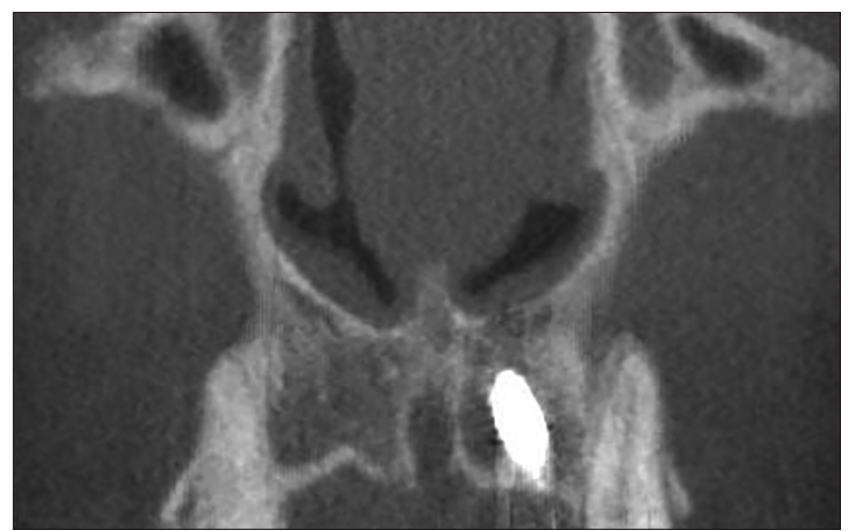

Fig. 4. Cone-beam computed tomography. The partial bone destruction of the nasal floor was confirmed. The chronic inflammation and local osteomyelitis were observed above the maxillary left lateral incisor implant.

Sang Min Lee et al: Nasal septal abscess with a dental origin: a case report and a review of the literature. J Korean Assoc Oral Maxillofac Surg 2021

day, intravenously), amikacin $250 \mathrm{mg} / 2 \mathrm{~mL} / \mathrm{vial}$ (Shinpoong, Ansan, Korea; one vial, three times a day, intravenously) The patient's body temperature was $36.8^{\circ} \mathrm{C}$, white blood cell (WBC) count was 18,150 leukocytes $/ \mu \mathrm{L}$, high sensitivity Creactive protein (hsCRP) level was $74 \mathrm{mg} / \mathrm{L}$, and erythrocyte sedimentation rate (ESR) was $104 \mathrm{~mm} / \mathrm{hr}$. Over 2 days, nasal septal swelling persisted, and daily aspiration and pus culture were performed.

Panoramic view (Fig. 3) and additional cone-beam CT (CBCT) (Fig. 4) were performed. Using panoramic view, an extracted left upper central incisor was confirmed. CBCT revealed chronic inflammation and localized osteomyelitis of the left upper lateral implantation apex area, as well as partial bone destruction of the nasal floor. When the patient visited our department, the left upper central incisor had been extracted. On the 3rd day of admission, intra-oral incision and drainage were performed and removed moderate yellowish 
pus. Klebsiella pneumoniae was detected in the pus culture. Despite antibiotic therapy and surgical drainage, laboratory test results were not remarkably improved, and the patient's nasal breathing remained obstructed. On the 10th day of admission, incision and drainage through the nasal septal mucosa were performed. Biopsy results revealed chondroid tissue with hemorrhagic necrosis (necrotizing inflammation). Body temperature remained within the normal range, except on the 2 nd day of admission when it reached $37.8^{\circ} \mathrm{C}$. The patient was admitted to our department for 2 weeks of triple antibiotic therapy. On completion of the therapy, blood cell counts were improved: WBC count was 4,810 leukocytes $/ \mu \mathrm{L}$, hsCRP was $0.4 \mathrm{mg} / \mathrm{L}$, and ESR was $51 \mathrm{~mm} / \mathrm{hr}$. However, the patient was referred to the otorhinolaryngology department because of continuous nasal septal swelling and obstruction.

Approximately $1 \mathrm{~cm} \times 1 \mathrm{~cm}$-sized pinkish-colored, round edematous swelling was found in both anterior portions of the nasal septum. The patient was referred to the otorhinolaryngology department and diagnosed with nasal septal hematoma. Under local anesthesia, curettage, irrigation, trans-septal suture, and merocele packing were performed via an intranasal approach. During surgery, a partial defect of the anterior nasal septal cartilage was found. Also, a large amount of serous bloody-colored fluid was discharged; however, the result of culture showed "no growth for two days". The patient was discharged after 1 week of hospitalization with patency of the bilateral nasal airway.

After a 2-month follow-up, the patient showed no evidence of infection or nasal deformity.

In the present study, two authors (D.H.L. and S.M.L.) independently searched PubMed for relevant articles regardless of year and country using the terms: ("nasal septal abscess") OR ("nasal septum abscess"). The search was conducted on June 1, 2019. Initially, 229 articles were identified from the database, of which 13 related articles were selected via title and abstract screening. All articles were case reports. Two articles unrelated to the field of dentistry were excluded through full text readings. All discrepancies related to the qualification criteria were resolved through discussion. Articles that were not in English (Chinese=1, French=2, Portuguese=1) were excluded. Additionally, two articles were included via reference lists. Finally, a total of nine articles (10 patients) was selected. After adding the present case, 10 articles (11 patients) were chosen for detailed review and data extraction.

The following data were independently extracted from each eligible article by the two authors (D.H.L. and S.M.L.): first author, year of publication, age, sex, previous dental his- tory or findings, pathology, treatment or medication, followup period, and complications ${ }^{1-6,12-14}$.(Table 1)

The age of the patients ranged from 7 to 69 years (mean, 32.82 years; standard deviation, \pm 23.86 years). The sex composition of the patients was males $(n=7 ; 63.6 \%)$, females $(\mathrm{n}=4 ; 36.4 \%)$. Previous dental history findings related to NSAs included periapical lesions $(\mathrm{n}=2 ; 18.2 \%)$, dental caries $(n=2 ; 18.2 \%)$, previous tooth extraction $(n=3 ; 27.3 \%)$, previous root canal therapy $(n=2 ; 18.2 \%)$, cystic lesions $(n=1$; $9.1 \%)$, and dental trauma $(n=1 ; 9.1 \%)$. The distribution of the tooth related to NSA were maxillary incisor $(n=9 ; 81.8 \%)$, maxillary premolar $(n=1 ; 9.1 \%)$, and impacted tooth of the premaxillary area $(n=1 ; 9.1 \%)$, revealing clear dominance of the maxillary incisor.(Table 2)

\section{Discussion}

Although NSA can occur as a result of infection of any neighboring structure, the most frequent cause is infection of the nasal septal hematoma after accidental or surgical trauma $^{9-11}$. If NSA is not diagnosed and promptly treated, it can lead to severe and life-threatening complications. Possible complications include cavernous sinus thrombosis, meningitis, brain abscess, and periorbital cellulitis/abscess as well as deformity of the nasal area ${ }^{6,11}$. Trauma is a common cause of septal hematoma, which can develop into NSA if not diagnosed or properly treated in time. Up to $85 \%$ of NSAs are caused by an infected septal hematoma secondary to nasal trauma $^{11,15}$. Less common causes, apart from nose and sinus infection, are dental infection and complication of nasal surgery $^{11,16}$

In the present case, it was presumed that the inflammation present in the apex of the left upper central incisor was diffused into the nasal septal area by the pressure of the local anesthesia injection at the time of extraction and subsequently developed into NSA. CBCT revealed that the apices of the extracted left upper central incisor and left upper lateral implant were extremely close, which might have deteriorated the underlying chronic inflammation and osteomyelitis.

Nontraumatic or spontaneously occurring NSA has been reported mainly in immunocompromised patients ${ }^{10,17,18}$. Most case are pediatric because of frequent nasal trauma in children $^{19}$. Nasal trauma causes rupture of the small vessels to the nasal septum, and blood collects to separate the cartilage and mucoperichondrium. Ischemia and increased tissue pressure destroy the cartilage. Further, blood accumulation provides an ideal medium for bacterial growth, and infection 


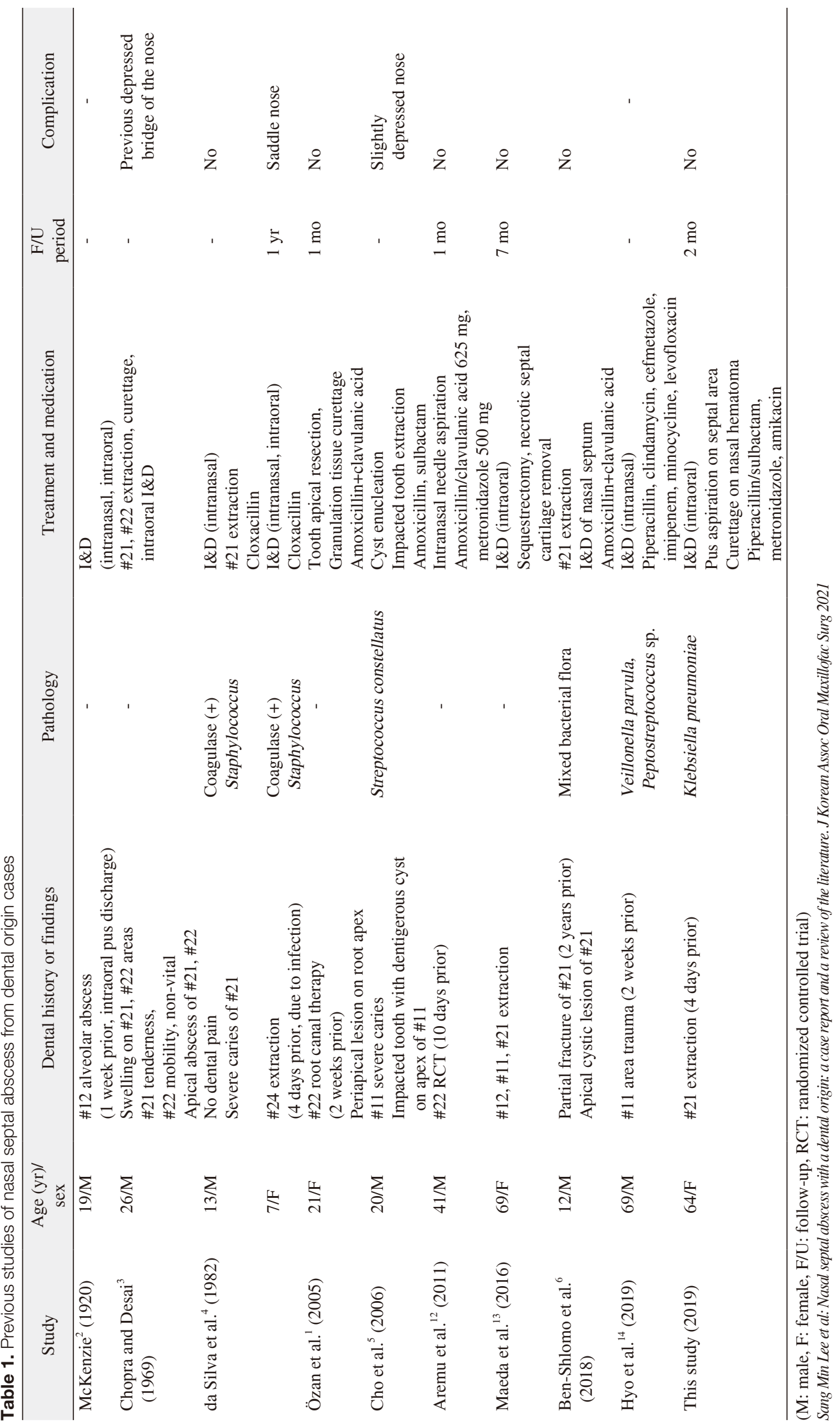


Table 2. Summary of reviewed articles regarding nasal septal abscess from dental origin cases including the present case

\begin{tabular}{lc}
\hline \multicolumn{1}{c}{ Variable } & Value \\
\hline No. of patients & 11 \\
Sex & $7(63.6)$ \\
Male & $4(36.4)$ \\
Female & $32.82 \pm 23.86$ \\
Age $(y r)$ & $5(45.5)$ \\
$0-20 \mathrm{yr}$ & $2(18.2)$ \\
$21-40 \mathrm{yr}$ & $4(36.4)$ \\
$41-60 \mathrm{yr}$ & $2(18.2)$ \\
Etiology & $2(18.2)$ \\
Periapical lesion & $3(27.3)$ \\
Caries & $2(18.2)$ \\
Previous extraction & $1(9.1)$ \\
Root canal therapy & $1(9.1)$ \\
Cystic lesion & \\
Dental trauma & $9(81.8)$ \\
Related tooth & $1(9.1)$ \\
Maxillary incisor & $1(9.1)$ \\
Maxillary premolar & \\
Impacted tooth of premaxillary area & $3(27.3)$ \\
Complication & $6(54.5)$ \\
Saddle nose & $2(18.2)$ \\
No &
\end{tabular}

Values are presented as number only, number (\%), or mean \pm standard deviation.

Sang Min Lee et al: Nasal septal abscess with a dental origin: a case report and a review of the literature. J Korean Assoc Oral Maxillofac Surg 2021

of the hematoma can occur within 3 days and cause cartilage necrosis within $24-48$ hours $^{10,11,19}$. Eventually, this leads to nasal cartilage destruction and septal perforation, which can lead to cosmetic sequelae such as septal deformity and saddle nose ${ }^{10,16}$. It can cause significant damage in relation to nasal patency and growth ${ }^{7}$. Staphylococcus aureus is the most common infectious microorganism, found in about $70 \%$ in of cases. Other relatively common microorganisms include Haemophilus influenzae, group A $\beta$-hemolytic streptococcus, Streptococcus pneumoniae, and other Streptococcus sp. ${ }^{11}$. Less frequently observed microorganisms are Klebsiella pneumoniae, Enterobacteriaceae, Streptococcus milleri, and anaerobic bacteria ${ }^{11}$.

The purpose of NSA treatment is to prevent infectious complications and avoid destruction of the nasal septal cartilage ${ }^{10}$. Therefore, if NSA is diagnosed, rapid decompression of subperiochondrial blood collection should be performed through surgical incision and drainage ${ }^{10}$. In addition, empirical systemic antibiotics should be administered immediately, starting with broad-spectrum antibiotics. In general, augumentin, penicillin, cloxacillin, and cefuroxime are used for the most common pathogens in NSAs. Furthermore, culturebased antibiotics are recommended when patients show no improvement or deterioration despite the use of common an- tibiotics. Some clinicians recommend the use of gentamycin to cover gram-negative bacteria, whereas others recommend the use of metronidazole in the presence of infections with a dental origin ${ }^{11}$. If nose deformity is present, further reconstruction surgical repair might be required.

In conclusion, NSA is most commonly caused by trauma, followed by dental infection and spontaneous occurrence without an underlying cause. Early diagnosis and treatment are required because NSA can lead to serious potential complications. In the present case, there was no history of facial trauma except extraction of the maxillary right central incisor 4 days prior. NSA was diagnosed by aspiration of the nasal septal area and enhanced CT. It is believed that inflammation around the teeth existed before extraction and spread to the nasal septum by factors such as the pressure caused by the injection at the time of extraction and subsequently developed into NSA. If NSA is suspected in patients without facial trauma, careful examination of the teeth, especially the maxillary incisor area, and the possibility of dental origin should be considered.

\section{ORCID}

Sang Min Lee, https://orcid.org/0000-0002-6033-426X

Dae Ho Leem, https://orcid.org/0000-0001-6735-8275

\section{Authors' Contributions}

S.M.L. participated in data collection and wrote the manuscript. D.H.L. participated in study design and helped to draft the manuscript.

\section{Consent for Publishing Photographs}

Written informed consent was obtained from the patients for publication of this article and accompanying images.

\section{Conflict of Interest}

No potential conflict of interest relevant to this article was reported.

\section{References}

1. Özan F, Polat S, Yeler H. Nasal septal abscess caused by dental infection: a case report. Internet J Dent Sci 2005;3:1-4.

2. McKenzie D. Dental abscess of the nasal septum. Proc R Soc Med 
1920;13(Laryngol Sect):161-2.

3. Chopra SS, Desai NT. Nasal septal abscess due to infection from upper incisors. J Indian Dent Assoc 1969;41:249-50.

4. da Silva M, Helman J, Eliachar I, Joachims HZ. Nasal septal abscess of dental origin. Arch Otolaryngol 1982;108:380-1. https:// doi.org/10.1001/archotol.1982.00790540052015

5. Cho JG, Lim HW, Zodpe P, Kang HJ, Lee HM. Nasal septal abscess: an unusual presentation of dentigerous cyst. Eur Arch Otorhinolaryngol 2006;263:1048-50. https://doi.org/10.1007/s00405006-0105-z

6. Ben-Shlomo N, El-Saied S, Schneider S. Nasal septal abscess of dental origin - a case report and review of the literature. Int J Pediatr Otorhinolaryngol Case Reports 2018;21:12-4. https://doi. org/10.1016/j.pedeo.2018.07.001

7. Dispenza C, Saraniti C, Dispenza F, Caramanna C, Salzano FA. Management of nasal septal abscess in childhood: our experience. Int J Pediatr Otorhinolaryngol 2004;68:1417-21. https://doi. org/10.1016/j.ijporl.2004.05.014

8. Ambrus PS, Eavey RD, Baker AS, Wilson WR, Kelly JH. Management of nasal septal abscess. Laryngoscope 1981;91:575-82. https://doi.org/10.1288/00005537-198104000-00010

9. Beck AL. Abscess of the nasal septum complicating acute ethmoiditis. Arch Otolaryngol 1945;42:275-9. https://doi.org/10.1001/ archotol.1945.00680040359006

10. Walker R, Gardner L, Sindwani R. Fungal nasal septal abscess in the immunocompromised patient. Otolaryngol Head Neck Surg 2007;136:506-7. https://doi.org/10.1016/j.otohns.2006.07.022

11. Alshaikh N, Lo S. Nasal septal abscess in children: from diagnosis to management and prevention. Int J Pediatr Otorhinolaryngol 2011;75:737-44. https://doi.org/10.1016/j.ijporl.2011.03.010

12. Aremu SK, Alabi BS, Omokanye HO. Dentogenic nasal septal abscess. Ear Nose Throat J 2011;90:E27-8. https://doi. org/10.1177/014556131109000321
13. Maeda M, Matsunobu T, Kurioka T, Kurita A, Shiotani A. A case of nasal septal abscess caused by medication related osteonecrosis in breast cancer patient. Auris Nasus Larynx 2016;43:93-6. https:// doi.org/10.1016/j.anl.2015.04.006

14. Hyo Y, Fukushima H, Harada T, Hara H. Nasal septal abscess caused by anaerobic bacteria of oral flora. Auris Nasus Larynx 2019;46:147-50. https://doi.org/10.1016/j.anl.2018.05.014

15. Chukuezi AB. Nasal septal haematoma in Nigeria. J Laryngol Otol 1992;106:396-8. https://doi.org/10.1017/s0022215100119656

16. Huang YC, Hung PL, Lin HC. Nasal septal abscess in an immunocompetent child. Pediatr Neonatol 2012;53:213-5. https://doi. org/10.1016/j.pedneo.2012.04.011

17. Salam B, Camilleri A. Non-traumatic nasal septal abscess in an immunocompetent patient. Rhinology 2009;47:476-7. https://doi. org/10.4193/Rhino08.142

18. Shah SB, Murr AH, Lee KC. Nontraumatic nasal septal abscesses in the immunocompromised: etiology, recognition, treatment, and sequelae. Am J Rhinol 2000;14:39-43. https://doi. org $/ 10.2500 / 105065800781602975$

19. Cervera Escario J, Calderón Nájera R, Enríquez de Salamanca J, Bartolomé Benito M. [Post-traumatic haematoma and abscess in the nasal septa of children]. Acta Otorrinolaringol Esp 2008;59:139-41. Spanish.

How to cite this article: Lee SM, Leem DH. Nasal septal abscess with a dental origin: a case report and a review of the literature. J Korean Assoc Oral Maxillofac Surg 2021;47:135-140. https://doi. org/10.5125/jkaoms.2021.47.2.135 